\title{
HPLC-UV/FD Methods for Scopoletin and Asiatic acid: Development, Validation and Application in WHO Recommended Stability Testing of Herbal Drug Products
}

\author{
Nancy Yogita Bansal and Gulshan Bansal*
}

Department of Pharmaceutical Sciences and Drug Research, Punjabi University, Patiala, India

\begin{abstract}
WHO recommended accelerated stability study was conducted on commercially available herbal products containing Shankhpushpi along with Bacopa monnieri (A) or Centella asiatica (B) at a temperature of $40 \pm 2^{\circ} \mathrm{C}$ and $75 \pm 5 \% \mathrm{RH}$ for six months. Control sample of each product was stored at $4^{\circ} \mathrm{C}$. Stability samples were withdrawn after 1, 3 and 6 months. Each control and stability sample was analysed for the content of scopoletin, asiatic acid and bacoside A by HPLC methods because such methods prove more selective, sensitive, efficient, reproducible, and accurate than spectroscopic and chemical methods. These methods also have advantages of sample handing, cost effectiveness and versatility in analyzing chemically diverse compounds over other methods like GSC and GLC. New methods developed and validated for scopoletin and asiatic acid were proved sufficiently precise, accurate and robust for analysis of scopoletin $(1-500 \mathrm{ng} / \mathrm{ml})$ and asiatic acid $(10-1000 \mu \mathrm{g} / \mathrm{ml})$. Bacoside $A$ was not detected in any of the control samples of products $A$, indicating that $B$. monnieri is either absent in $A$ or the content of Bacoside $A$ is too low to be detectable. Content of scopoletin and asiatic acid was found to vary widely among different batches as well as products (scopoletin 165.78-206.15 ng/ml in A and 2.61-28.78 ng/ml in B, and asiatic acid 30.14-44.92 $\mu \mathrm{g} / \mathrm{ml}$ in B), which indicate a probable variability in therapeutic efficacy of the products. The content of markers decreased significantly after 6 months of storage under accelerated conditions, which implies that therapeutic efficacy of the product may also decrease substantially with storage. These findings further suggest real time stability studies as per the WHO and ICH guidelines involving marker's quantification and evaluation of therapeutic effects through appropriate in vitro/in vivo methods to establish actual shelf life of the products.
\end{abstract}

Keywords: Shankhpushpi; Centella asiatica; Brahmi; Convolvulus pluricaulis; Stability studies

\section{Introduction}

Central nervous system (CNS) active herbal drug products contribute significantly to global herbal drug market [1]. These are consumed indiscriminately by population of all age groups without any prescription in developing countries. Centella asiatica, Bacopa monnieri and Convolvulus pluricaulis are amongst the most widely used CNS active herbs. C. asiatica exert significant neuroprotective effect against oxidative damage due to derivatives of asiatic acid present in it. Clinical studies of its extracts justify its use as CNS active drug [2]. C. pluricaulis, commonly known as shankhpushpi in Indian System of Medicine, is popularly used for its tranquilizing and memory enhancing properties. Evolvulus alsinoides, Clitorea ternatea and Canscora decussate are the other herbs commonly named as Shankhpushpi in Indian System of Medicine. These plants contain several different alkaloids, flavanoids and coumarins as active chemicals that bring about their different biological effects [3]. Scopoletin is one of the active constituents present in C. pluricaulis, E. alsinoides and C. decussata, and is reported to have memory enhancing properties [4]. Bacopa monnieri, popularly known as Brahmi, is widely used CNS active herb. It is clinically proven to exhibit nootropic effect. One of the active constituents known for its CNS activity is bacoside A [5].

A large number of herbal products derived from these herbs $(C$. asiatica, B. monnieri and C. pluricaulis) are available in market. These products bear a shelf life of 2-3 years as suggested for different types of herbal formulations, irrespective of their constituent herbs, in Drugs and Cosmetic (Amendment) Rules in India [6]. The international drugs regulatory bodies such as World Health Organization (WHO), European Medicines Agency (EMEA) and United States Food and Drug Administration (US-FDA) have laid down specific guidelines for establishing safety and efficacy of herbal products through systematic standardization and stability studies [7-15]. All these guidelines consensually recommend conduct of stability studies on any herbal drug product under the conditions as recommended in $\mathrm{ICH}$ guidelines for stability testing of drug substances and products [16]. Despite these guidelines, stability testing of herbal drug products is not carried out under the recommended conditions and as per the recommended time schedule. To the best of our knowledge from the literature search, there is no report on any stability testing of any of the four herbs commonly known as shankhpushpi. Inamdar et al. [17] conducted a stability study on different formulations of $C$. asiatica under different conditions of temperature and humidity (air conditioned, $25^{\circ} \mathrm{C}$, room temperature, $30^{\circ} \mathrm{C}, 40^{\circ} \mathrm{C}$, and $\left.40^{\circ} \mathrm{C}+80 \% \mathrm{RH}\right)$ and evaluated their stability in terms of the percent decrease in content of asiatic acid and asiaticoside (the CNS active markers), and madecassic acid and madecassoside (the CNS inactive markers). Nonetheless, the conditions and duration for this study are not in compliance with regulatory guidelines. Phrompittayarat et al. [18] have reported a study on stability testing on

*Corresponding author: Gulshan Bansal, Department of Pharmaceutical Sciences and Drug Research, Punjabi University, Patiala, India, Tel: +91175-3046255; Fax: +91-175-2283073; E-mail: gulshanbansal@rediffmail.com; gulshanbansal@gmail.com

Received: July 15, 2015; Accepted: September 12, 2015; Published September 14,2015

Citation: Bansal NY, Bansal G (2015) HPLC-UV/FD Methods for Scopoletin and Asiatic acid: Development, Validation and Application in WHO Recommended Stability Testing of Herbal Drug Products. Biochem Anal Biochem 4: 207. doi:10.4172/21611009.1000207

Copyright: $\odot 2015$ Bansal NY, et al. This is an open-access article distributed under the terms of the Creative Commons Attribution License, which permits unrestricted use, distribution, and reproduction in any medium, provided the original author and source are credited. 
B. monnieri, but conditions for testing are not in line with guidelines, and also duration is just 28 days. Other accelerated and long term stability studies on crude plant material of B. monnieri revealed that content of Bacoside A and Bacopaside I under accelerated conditions decreased by about $74 \%$ and $69 \%$, respectively after 6 months, and under long term conditions, it decreased by $75 \%$ and $80 \%$, respectively after 12 months $[19,20]$. These results indicated that $B$. monnieri is very unstable drug, and products containing it may not have shelf life more than 3 months. Moreover, a large number of HPLC methods for quantitation of asiatic acid, Bacoside $\mathrm{A}$ and scopoletin individually are reported in literature, which are summarised in Tables 1 and 2. These literature analyses revealed that though reliable method is available for stability testing of B. monnieri [18], no method is available for stability testing of shankhpushpi and C. asiatica.

HPLC has become a primary technique for analysing analytes especially in biological and heterogeneous samples. It allows accurate quantification of any analyte, without being isolated in pure form, by appropriate selection of stationary and mobile phases (polar to non-polar, $\mathrm{pH}$ ranging from 2-10), and detector (non-specific to highly specific). These methods are more selective, sensitive, efficient, reproducible, and accurate than the spectroscopic and chemical methods. Coupling of HPLC with a mass detector can increase the sensitivity to as low as picograms per unit volume or mass of sample. HPLC methods also have advantages over GC (gas chromatographic) methods. These include ease of sample handing (no need to convert the sample into vapour phase), low analysis cost (ultra high pure gases as mobile phase cost more than HPLC solvents), versatility in analyzing different type of compounds (both volatile as well as high melting solids) [45]. Hence, the present study was designed to develop and validate isocratic HPLC method(s) for quantification of scopoletin, bacoside $\mathrm{A}$ and asiatic acid containing B. monnieri, C. asiatica and shankhpushpi, and for its application in stability testing of products of these herbs in accordance with WHO guidelines. In pursuance of this objective, we have developed and validated separate, efficient and sensitive isocratic HPLC methods for detection and quantification of scopoletin and asiatic acid in order to analyze samples of the drug products generated during their stability studies. Comparison of the present method with the methods reported for asiatic acid in literature revealed that the present method is as fast as Method no. 11 [30] (Rt of $9 \mathrm{~min}$ versus $8 \mathrm{~min}$, Table 1), and has the advantages of employing simpler mobile phase with isocratic elution and using higher detection wavelength (200 nm versus $206 \mathrm{~nm}$ ). Fluorescence detector is more about 1000 times more sensitive due to improved signal to noise ratio, and highly selective due to use of emission spectrum than a UV-VIS detector [46]. Scopoletin meets all the requirements of compound to be detectable through fluorescence spectrum, and there are three HPLC methods employing fluorescent detector (FD as mentioned in Table 2. The present method has proved advantageous over the known HPLCFD methods in terms of its speed (Rt 25-35 min versus $8.5 \mathrm{~min}$ ) and mode of elution (Gradient versus Isocratic) (Table 2).

\section{Materials and Methods}

\section{Materials}

Three batches (designated as I, II and III) of each of the two types of Shankhpusphi syrups i.e., A (Shankhpushpi + B. monnieri) and $\mathrm{B}$ (C. pluricaulis + C. asiatica) were purchased from local pharmacy store. Methanol and acetonitrile (HPLC grades) were obtained from Merck Specialist Pvt. Ltd. (Mumbai, India). Scopoletin and asiatic acid were procured from Sigma Aldrich, (Chandigarh, India). Bacoside A

\begin{tabular}{|c|c|c|c|c|c|}
\hline S.No. & $\begin{array}{c}\text { Detection } \\
\text { wavelength } \\
(\mathrm{nm})\end{array}$ & Mobile phase & $\begin{array}{c}\text { Flow (ml/ } \\
\text { min) }\end{array}$ & Rt (min) & Reference \\
\hline 1. & 220 & ACN: $\mathrm{H}_{2} \mathrm{O}$; Gradient & 1.4 & 26.87 & [17] \\
\hline 2. & 206 & $\begin{array}{c}\text { ACN: } \mathrm{CH}_{3} \mathrm{O} \mathrm{C}\left(\mathrm{CH}_{3}\right)_{3}(0.1 \% \\
\text { TFA); Gradient }\end{array}$ & 1.0 & 50 & [21] \\
\hline 3. & 205 & $\mathrm{H}_{2} \mathrm{O}: \mathrm{ACN} ; 0.05 \% \mathrm{H}_{3} \mathrm{PO}_{4}$ & 0.8 & 24.2 & [22] \\
\hline 4. & 205 & $0.05 \% \mathrm{H}_{3} \mathrm{PO}_{4}: \mathrm{ACN}$ & 1.0 & 13.57 & [23] \\
\hline 5. & 217 & $\begin{array}{c}\mathrm{CH}_{3} \mathrm{OH}: \mathrm{ACN}: \mathrm{H}_{2} \mathrm{O} ; \\
\quad(5: 57: 38, \mathrm{v} / \mathrm{v})\end{array}$ & 1.0 & 19.6 & [24] \\
\hline 6. & 206 & ACN: $\mathrm{H}_{2} \mathrm{O}$; Gradient & 1.0 & $\sim 30$ & [25] \\
\hline 7. & 214 & $\mathrm{CH}_{3} \mathrm{OH}: \mathrm{H}_{2} \mathrm{O}=(75: 25 \% \mathrm{v} / \mathrm{v})$ & 0.8 & 19 & [26] \\
\hline 8. & 210 & ACN: Phosphate buffer & 1.8 & 18.4 & [27] \\
\hline 9. & 205 & ACN: $\mathrm{H}_{2} \mathrm{O}$; Gradient & 1.0 & 16.27 & [28] \\
\hline 10. & 205 & $\mathrm{ACN}: \mathrm{H}_{2} \mathrm{O}$; Gradient & 1.0 & 16.30 & [29] \\
\hline 11. & 200 & $\begin{array}{l}\text { (a) } \mathrm{ACN} / \mathrm{CH}_{3} \mathrm{OH}(7: 2) \text { and } \\
\text { (b) d. } \mathrm{w} / \mathrm{H}_{3} \mathrm{PO}_{4},(85 \%) \\
\text { premixed by } 42: 58 .\end{array}$ & 1.0 & $9.0 \mathrm{~min}$ & {$[30]$} \\
\hline 12. & 206 & $\begin{array}{c}\text { ACN: Phosphate buffer (20 } \\
\text { mM, pH 3.5) (55:45) }\end{array}$ & 1.0 & $8 \mathrm{~min}$ & $\begin{array}{l}\text { Present } \\
\text { Method }\end{array}$ \\
\hline
\end{tabular}

Table 1: Literature reports on HPLC-UV methods for asiatic acid.

\begin{tabular}{|c|c|c|c|c|c|}
\hline S.No. & Detection & Mobile phase & $\begin{array}{l}\text { Flow }(\mathbf{m l} / \\
\text { min) }\end{array}$ & $\begin{array}{c}\mathbf{R t} \\
(\mathbf{m i n})\end{array}$ & Reference \\
\hline 1. & $344 \mathrm{~nm}$ & $\begin{array}{c}\mathrm{CH}_{3} \mathrm{OH}: \\
\text { Gradient }\end{array} 0.05 \mathrm{~mol} / \mathrm{KH}_{2} \mathrm{PO}_{4}$ & 0.5 & 14.52 & [31] \\
\hline 2. & $345 \mathrm{~nm}$ & $\begin{array}{c}\mathrm{CH}_{3} \mathrm{OH} \text { and } \mathrm{H}_{2} \mathrm{O}(49: 51, \mathrm{v} / \mathrm{v}) \\
0.05 \%(\mathrm{v} / \mathrm{v}) \mathrm{H}_{3} \mathrm{PO}_{4}\end{array}$ & 1.0 & 5.1 & [32] \\
\hline 3. & $345 \mathrm{~nm}$ & $\begin{array}{c}80 \% 0.05 \mathrm{M} \mathrm{NH}_{4}\left(\mathrm{CH}_{3} \mathrm{COO}\right)-4.25: \\
20 \% \mathrm{ACN}\end{array}$ & 1.0 & 4.97 & [33] \\
\hline 4. & $366 \mathrm{~nm}$ & $\begin{array}{c}\mathrm{CH}_{3} \mathrm{OH}: \mathrm{H}_{2} \mathrm{O}(0.1 \% \mathrm{v} / \mathrm{v} \mathrm{HCOOH}) \\
3: 7\end{array}$ & 1.0 & 19.58 & [34] \\
\hline 5. & $300 \mathrm{~nm}$ & $\begin{aligned} 55: & 45(\% \mathrm{v} / \mathrm{v}) \mathrm{CH}_{3} \mathrm{OH}: \mathrm{H}_{2} \mathrm{O} \\
& \left(0.1 \% \mathrm{CH}_{3} \mathrm{COOH}\right)\end{aligned}$ & 1.0 & 4.6 & [35] \\
\hline 6. & $220 \mathrm{~nm}$ & $\mathrm{CH}_{3} \mathrm{OH}: \mathrm{H}_{2} \mathrm{O}(0.05 \% \mathrm{HCOOH})$ & 1.0 & 7.87 & [36] \\
\hline 7. & $345 \mathrm{~nm}$ & $\begin{array}{c}\text { (A) } \mathrm{H}_{2} \mathrm{O}: \mathrm{H}_{3} \mathrm{PO}_{4}(99.7: 0.3 \% \mathrm{v} / \mathrm{v}) \\
\text { (B) } \mathrm{ACN}: \mathrm{H}_{2} \mathrm{O}: \mathrm{H}_{3} \mathrm{PO}_{4} \\
\text { (79.9:20:0.3\% v/v) } \\
\text { Method-A:B }(75: 25 \% \mathrm{v} / \mathrm{v})\end{array}$ & 1.0 & 6.03 & [37] \\
\hline 8. & $360 \mathrm{~nm}$ & $\begin{array}{c}10 \% \mathrm{ACN}(A), 50 \% \text { ACN }(B) \text { and } \\
90 \% \mathrm{ACN}(C) ; \text { Gradient. }\end{array}$ & 1.0 & $\sim 26$ & [38] \\
\hline 9. & 320 nm & $\begin{array}{c}0.1 \% \mathrm{HCOOH} \text { and } \mathrm{ACN}, \\
\text { Gradient }\end{array}$ & 1.0 & $\sim 27$ & [39] \\
\hline 10. & $345 \mathrm{~nm}$ & $\begin{array}{c}\text { (A) } \mathrm{ACN}: \mathrm{CH}_{3} \mathrm{OH}(11: 5 \% \mathrm{v} / \mathrm{v}) \\
\text { (B) } 0.1 \% \mathrm{HCOOH} \\
\text { (m/v); Gradient }\end{array}$ & $\begin{array}{c}\text { Variable; } \\
0.6-1.4\end{array}$ & $>32$ & [40] \\
\hline 11. & $280 \mathrm{~nm}$ & $\mathrm{CH}_{3} \mathrm{COOH}$ and $\mathrm{CH}_{3} \mathrm{OH}$; Gradient. & 1.0 & $\sim 20$ & [41] \\
\hline 12 & $\begin{array}{c}\lambda e x-342 \\
\mathrm{~nm}, \lambda \mathrm{em}- \\
464 \mathrm{~nm}\end{array}$ & $\mathrm{CH}_{3} \mathrm{COOH}: \mathrm{ACN}$; Gradient & 2.0 & $\sim 7.5$ & [42] \\
\hline 13. & $\begin{array}{c}\lambda e x-340 \\
\mathrm{~nm}, \lambda \mathrm{em}- \\
425 \mathrm{~nm}\end{array}$ & $\begin{array}{c}\mathrm{H}_{2} \mathrm{O} \text { and } \mathrm{ACN} ; 3 \% \mathrm{CH}_{3} \mathrm{COOH} ; \\
\text { Gradient }\end{array}$ & 1.0 & 25 & [43] \\
\hline 14. & $\begin{array}{l}\lambda e x-340 \\
\mathrm{~nm}, \lambda \mathrm{em}- \\
460 \mathrm{~nm}\end{array}$ & $\begin{array}{c}50 \mathrm{mM} \mathrm{NH}_{4}\left(\mathrm{CH}_{3} \mathrm{COO}\right)(4.5) ; \\
\text { Gradient }\end{array}$ & 0.7 & $>35$ & [44] \\
\hline 15. & $\begin{array}{c}\lambda e x-357 \\
\mathrm{~nm}, \lambda \mathrm{em}- \\
425 \mathrm{~nm}\end{array}$ & $\begin{array}{c}\text { ACN:Phosphate buffer (20 mM, } \\
\text { pH 3.5) }(25: 75 \% \mathrm{v} / \mathrm{v})\end{array}$ & 1.0 & $\sim 8.5$ & $\begin{array}{l}\text { Present } \\
\text { Method }\end{array}$ \\
\hline
\end{tabular}

Table 2: Literature reports on HPLC methods for scopoletin

was obtained from Natural Remedies, (Bangalore, India). All other chemicals and solvents were procured from S.D. fine chemicals, (Mumbai, India). HPLC grade water obtained from Bio Age Direct Ultra water purification system (Bio-Age Equipments and Services, Mohali, India) was used for preparation of all reagents and solutions. 


\section{Instruments}

HPLC-UV and HPLC- fluorimetric analysis were carried out on a HPLC system consisting of a pump (515), Rheodyne manual injector, UV/Visible detector (2489) and multi wavelength flourescence detector (2475) (Waters, MA, USA). The data were acquired and processed in EMPOWER 2 software (Waters, MA, USA). The LC-PDA analyses were carried out on Waters HPLC system consisting of pumps (515), Rheodyne manual injector (Waters, Milford, MA, USA) and PDA detector (2998) controlled by EMPOWER 3 software (Waters, MA, USA). The chromatographic separations of the samples were achieved on NUCLEODUR C18 $(250 \mathrm{~mm} \times 4.6 \mathrm{~mm} ; 5 \mu \mathrm{m})$ column. Other columns used in the study included XTERRA C18 (250 mm x $4.6 \mathrm{~mm} ; 5$ $\mu \mathrm{m})$ column, KROMASIL C18 (250 mm x $4.6 \mathrm{~mm} ; 5 \mu \mathrm{m})$, YMC TACK ODS-AQ (250 mm x $4.6 \mathrm{~mm} ; 5 \mu \mathrm{m})$ column, INERTSIL C18 $(250 \mathrm{~mm}$ $\mathrm{x} 4.6 \mathrm{~mm} ; 5 \mu$ ) and CHROMOLITHIC HIGH RESOLUTION Column $(100 \mathrm{~mm} \times 4.6 \mathrm{~mm})$. The mobile phase was filtered through nylon membrane $(0.45 \mu \mathrm{m}, 47 \mathrm{~mm})$ using Millipore filtration assembly, and was degassed using transonic sonicator bath (570/H ELMA, Germany). Samples were lyophilized using lyophilizer (ALLIED FROST, Macflow Engineering, Pvt. Ltd., New Delhi, India). UV spectrophotometer (DU 640 B series, Beckman, USA) was used for spectrophotometric analysis. Fluorimetric analysis was carried out on SL-174 Spectrofluorometer (ELICO, Andhra Pradesh, India). The $\mathrm{pH}$ was measured using Digital pH meter (FIVE EASY PLUS FEP 20-ATC KIT, Mettler Toledo AG, Analytical, Schwerzenbach, Switzerland). Stability studies were conducted in a stability chamber capable of controlling temperature and humidity within range of $\pm 2^{\circ} \mathrm{C}$ and $\pm 5 \% \mathrm{RH}$, respectively (Rolex Scientific Engineers, Ambala, India). The chamber was set at temperature of $40^{\circ} \mathrm{C}$ and $75 \% \mathrm{RH}$.

\section{HPLC methods}

Standard solutions of scopoletin $(0.001 \mathrm{mg} / \mathrm{ml})$, asiatic acid $(0.1$ $\mathrm{mg} / \mathrm{ml})$ and bacoside A $(1 \mathrm{mg} / \mathrm{ml})$ in methanol were used for HPLC method development. Asiatic acid was separated on a NUCLEODUR C18 with mobile phase consisting of acetonitrile and Phosphate buffer $(20 \mathrm{mM}, \mathrm{pH} 3.5)(55: 45 \% \mathrm{v} / \mathrm{v})$ flowing at a rate of $1 \mathrm{ml} / \mathrm{min}$ using $206 \mathrm{~nm}$ as detection wavelength. Scopoletin was resolved on the same column with a mobile phase composed of acetonitrile and Phosphate buffer $(20 \mathrm{mM}, \mathrm{pH} 3.5)(25: 75 \% \mathrm{v} / \mathrm{v})$ flowing at a rate of 1 $\mathrm{ml} / \mathrm{min}$ using fluorescence detector with excitation wavelength of 357 $\mathrm{nm}$ and emission wavelength of $425 \mathrm{~nm}$. Five major peaks, which are characteristic of Bacoside A as reported by Phrompittayarat et al. [18], were optimally resolved on XTERRA C18 $(250 \times 4.6 \mathrm{~mm} ; 5 \mu \mathrm{m})$ column with a mobile phase consisting of acetonitrile and orthophosphoric acid in water $(0.2 \%)(65: 35 \% \mathrm{v} / \mathrm{v})$ at flow rate of $1 \mathrm{ml} / \mathrm{min}$. LC-PDA analyses of standard asiatic acid, scopoletin, and control samples of all six products were carried out to establish purity of asiatic acid and scopoletin peaks.

\section{Method validations}

HPLC methods for asiatic acid and scopoletin were validated by evaluating various validation parameters such as linearity, precision, accuracy, robustness, LOD and LOQ in accordance with ICH guidelines Q2(R1) [47]. Linearity was evaluated by analyzing standard solutions of asiatic acid $(10-1000 \mu \mathrm{g} / \mathrm{ml})$ and scopoletin $(1-500 \mathrm{ng} / \mathrm{ml})$ in increasing order of concentration. Calibration curves for each marker were plotted in triplicate to calculate slope, intercept and correlation coefficient (mean \pm standard deviation). The intraday precision was determined by analyzing three different concentrations covering the linearity range of asiatic acid and scopoletin. The inter-day precision was evaluated by analyzing the same three concentrations of both the markers on three different days. Each concentration was analyzed six times consecutively, and precision was expressed as percent relative standard deviation (\% RSD) of the calculated concentration. LOD and LOQ were determined by calibration curve method using following equations: $L O D=3.3$ $\sigma / \mathrm{S} ; \mathrm{LOQ}=10 \sigma / \mathrm{S}$; where $\sigma$ and $\mathrm{S}$ are standard deviation of slope and mean intercept, respectively. Subsequently, solutions of asiatic acid and scopoletin having concentrations equal to their LOD and LOQ were prepared, analyzed $(n=6)$, and\%RSD of the concentration found were calculated. Robustness of the methods was determined by making small and deliberate changes in various parameters of optimized chromatographic conditions such as composition of mobile phase (content of acetonitrile or buffer varied by $\pm 1 \% \mathrm{v} / \mathrm{v}), \mathrm{pH}( \pm 0.1)$, detection wavelengths $( \pm 5 \mathrm{~nm})$, flow rate $( \pm 0.1 \mathrm{ml} / \mathrm{min})$, and column brand. Standard solutions of markers were analyzed at each of varied chromatographic conditions. Content of markers and changes in their retention times (Rt) were determined vis-a-vis the optimized chromatographic conditions.

\section{Accelerated stability studies}

All six products (AI-AIII and BI-BIII) were placed in stability chamber maintained at accelerated stability conditions of $40 \pm 2^{\circ} \mathrm{C}$ and $75 \pm 5 \% \mathrm{RH}$. The control sample of each batch was stored at $4^{\circ} \mathrm{C}$. The stability samples were withdrawn after 1, 3 and 6 months. Control and each stability sample of each product were processed for estimation of asiatic acid, bacoside A and scopoletin as following: $\mathrm{A} 5 \mathrm{ml}$ portion of each control and stability sample was lyophilized. The resultant sticky mass was mixed with $5 \mathrm{ml}$ of methanol and sonicated for $15 \mathrm{~min}$. The methanolic solution was separated and transferred into an airtight sample vial. The residual sticky mass was again treated as before with fresh $5 \mathrm{ml}$ of methanol. The two aliquots of methanolic solutions were mixed in airtight sample vial. This resultant solution was used for quantification of asiatic acid and bacoside A. For scopoletin estimation, the resultant solution was diluted up to five times with methanol. Each final solution was filtered through membrane filter $(0.45 \mu, 13 \mathrm{~mm})$ before analysis.

\section{Results and Discussion}

In traditional system of medicine in India, Shankhpushpi (any of the four herbs as mentioned in Introduction section) is used in combination with brahmi (B. monnieri) to enhance memory and improve CNS functioning [48]. C. asiatica, commonly known as mandukparni, is widely used as a substitute for brahmi due to mistaken identity that occurred in $16^{\text {th }}$ century [49]. As a result of this mistaken identity, B. monnieri and $C$. asiatica are still used synonymously to produce products in combination with shankhpushpi. In addition, a vast majority of products claim to contain "Shankhpushpi" on its label, but without any reference to its specific biological name. Hence, in the present study, we have selected two products i.e., A (label claim: Shankhpushpi + B. monnieri) and B (label claim: C. pluricaulis + C. asiatica) for conducting stability studies in accordance with WHO and ICH guidelines. The studies were conducted on three batches (designated as I, II and III) of each of these two products as required by WHO guidelines. Scopoletin is a common CNS active marker for different botanical sources of shankhpushpi, bacoside A (composed of five components) is an active marker for B. monnieri, and asiatic acid is an active marker for $C$. asiatica. Hence, scopoletin, bacoside $A$ and asiatic acid were used as markers to assess stability of the selected products.

\section{Development and optimization of HPLC methods}

Standard solution of each marker were scanned over 200-400 nm 
to obtain a common wavelength for their simultaneous detection on HPLC. The three markers showed maximum absorbance at $206 \mathrm{~nm}$. Hence, it was selected as detection wavelength for HPLC method of these markers. A comparative study of various HPLC methods (Tables 1 and 2) indicated no significant similarity among any of the methods for scopoletin, bacoside A and asiatic acid. Hence, we started the HPLC method development for the selected markers by using a mobile phase composed of acetonitrile and water $(50: 50 \% \mathrm{v} / \mathrm{v})$ at a flow rate of $1 \mathrm{ml} /$ min on a KROMASIL column $(250 \times 4.6 \mathrm{~mm} ; 5 \mu \mathrm{m})$ using $206 \mathrm{~nm}$ as detection wavelength. Each of the three standard solutions was analyzed. Scopoletin and asiatic acid eluted at about 4 and $20 \mathrm{~min}$, respectively but bacoside A was not observed in the chromatogram even upto $60 \mathrm{~min}$ of run time. Subsequently, each of the six products (AI-AIII and BI-BIII) was analysed using same chromatographic conditions. Both scopoletin and asiatic acid were detected in products BI-BIII and only scopoletin was detected in AI-AIII. However, the scopoletin peak was found interfered by other peaks in the products, and asiatic acid peak was found as in standard solution. In order to improve resolution of scopoletin peak in the products, content of acetonitrile was decreased in the mobile phase. It was observed that with decrease in acetonitrile content, Rt of scopoletin shifted insignificantly but that of asiatic acid shifted enormously. Numerous other changes in mobile phase composition (replacement of acetonitrile with methanol and/or water with buffer, $\mathrm{pH}$, and various proportions of organic and aqueous components), and in analytical columns (YMC TACK ODS$\mathrm{AQ}, \mathrm{CHROMOLITH}$ and NUCLEODUR) produced no satisfactory resolution and elution pattern of the markers. The maximally improved resolution was observed on NUCLEODUR column. Using this column, different mobile phases were run in gradient mode to elute and resolve the three markers, but no success was achieved. After these exhaustive unsuccessful trials, it was understood that with the resources available, a single HPLC method for simultaneous elution of scopoletin, asiatic acid and bacoside A does not seem possible. Hence, we shifted our focus on development of separate but short HPLC methods for quantification of asiatic acid, scopoletin and bacoside A. Literature reports have
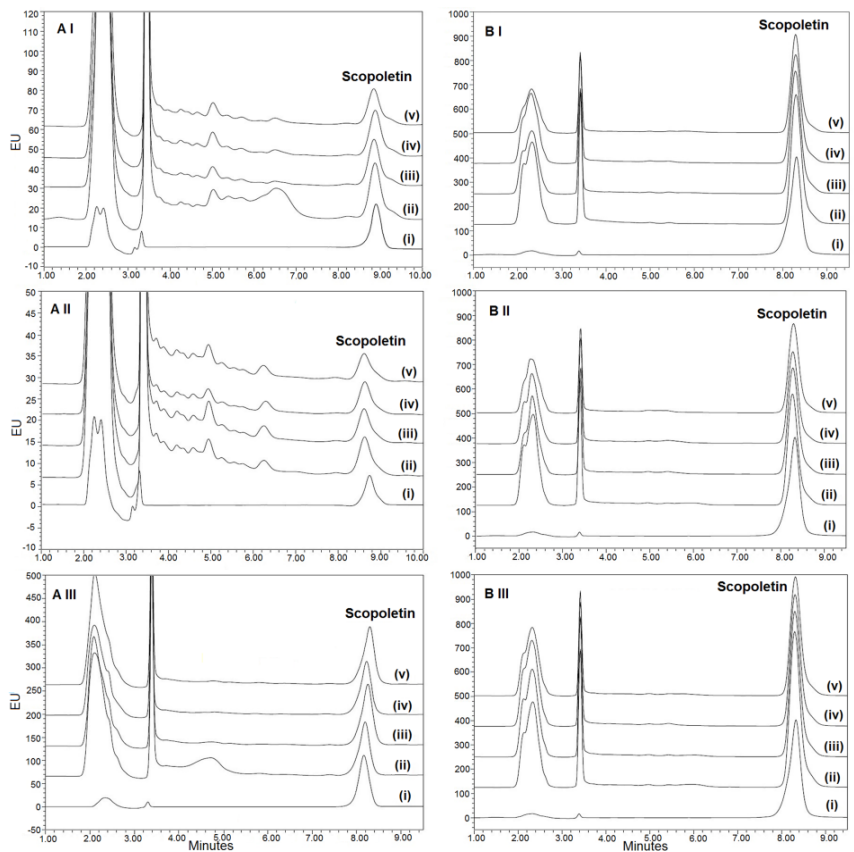

Figure 1: HPLC-FD chromatograms of scopoletin (i), 0 month (ii), 1 month (iii), 3 month (iv) and 6 month (v) stability sample of products Al - Alll and BI - BIII.
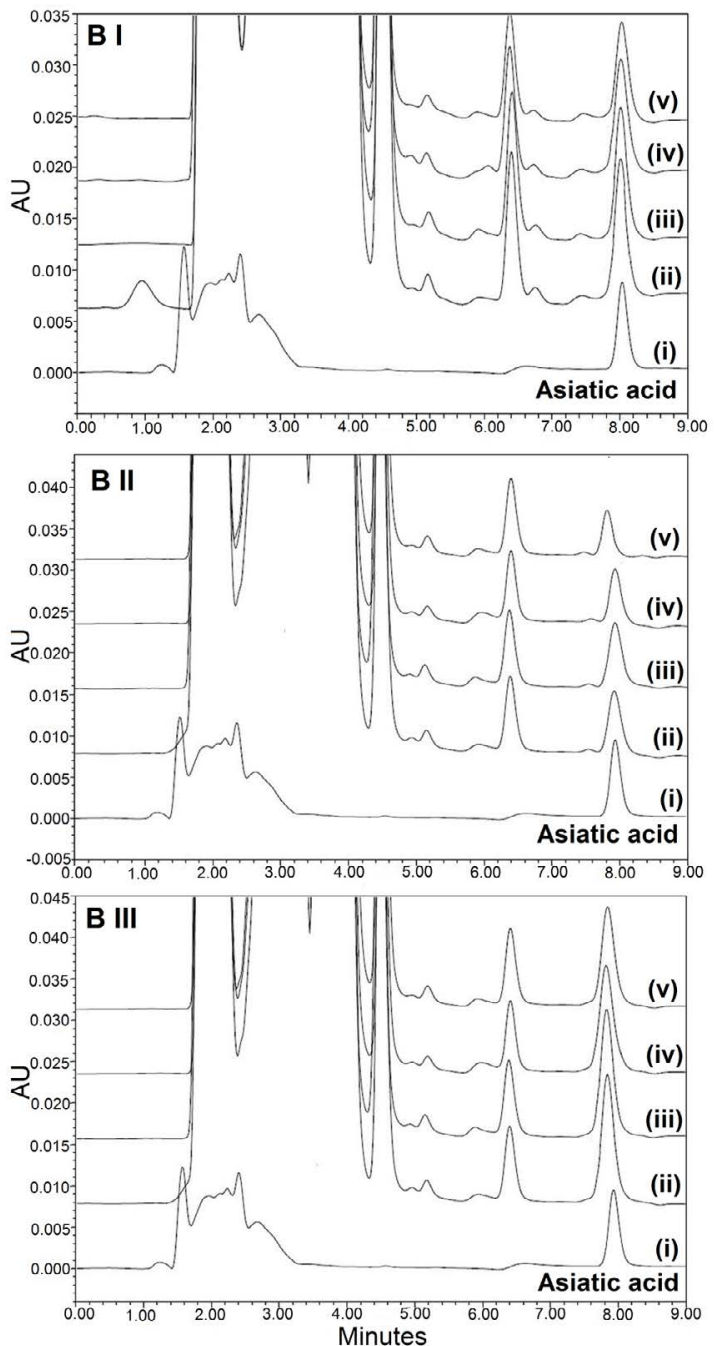

Figure 2: HPLC-UV chromatograms of asiatic acid (i), 0 month (ii), 1 month (iii), 3 month (iv) and 6 month (v) stability sample of products BI - BIII.

revealed that scopoletin exhibits fluorescence and is efficiently detected in fluorescence detector [50-52]. Hence, standard standard solution of scopoletin was read on spectroflourimeter to find the excitation and emission wavelengths ( $\lambda$ ex and $\lambda$ em) for it. These were found to be 357 $\mathrm{nm}$ and $425 \mathrm{~nm}$, respectively. From the results of various trials carried out as revealed earlier, a mobile phase composed of acetonitrile and phosphate buffer $(20 \mathrm{mM}, \mathrm{pH} 3.5)(25: 75 \% \mathrm{v} / \mathrm{v})$ was used at a flow rate of $1 \mathrm{ml} / \mathrm{min}$ to elute scopoletin on Nucleodur C18 column using fluorescence detector (FD) set at $\lambda$ ex and $\lambda$ em of $357 \mathrm{~nm}$ and $425 \mathrm{~nm}$, respectively. These chromatographic conditions eluted scopoletin at $8.4 \mathrm{~min}$ as a sharp peak, which was well resolved in each product (Figure 1). Incidentally, the mobile phase used is found quite similar to that reported by Muller-Enoch et al. for scopoletin [53], but the new method is found superior to the reported method in terms of detector (FD is more sensitive than UV detector) and buffer (Phosphate buffer is more stable than ammonium acetate buffer ). Asiatic acid was eluted as a sharp peak at $7.9 \mathrm{~min}$ (Figure 2) with a mobile phase composed of acetonitrile and phosphate buffer $(20 \mathrm{mM}, \mathrm{pH} 3.5)(55: 45 \% \mathrm{v} / \mathrm{v})$ flowing at a rate of $1 \mathrm{ml} / \mathrm{min}$ over NUCLEODUR C18 column using $206 \mathrm{~nm}$ as detection wavelength. This method is found more efficient (Rt $8 \mathrm{~min}$ ) than all HPLC methods (Rt 13-50 min) known in the literature reports 
(Table 1). Moreover, it has the advantages of using simpler mobile phase with isocratic elution and using higher detection wavelength $(200 \mathrm{~nm}$ versus $206 \mathrm{~nm}$ ) that reduces signal to noise ratio. These methods were used for analyses of control and stability samples of each product to determine the content of scopoletin (Figure 1) and asiatic acid (Figure 2). For bacoside A, the method as reported by Phrompittayarat et al. [18] was used as such. Briefly, it was eluted as a set of five distinct peaks with acetonitrile and phosphoric acid $(0.2 \%)(65: 35 \% \mathrm{v} / \mathrm{v})$ running at a rate of $1 \mathrm{ml} / \mathrm{min}$ on XTERRA C18 $(250 \times 4.6 \mathrm{~mm} ; 5 \mu \mathrm{m})$ column. However, bacoside $A$ was not detected even in concentrated control sample of any batch of product A. It suggested that B. monnieri is either not present in the product A (contrary to the label claim) or its concentration is so low that HPLC method is not useful for its detection.

\section{Method validation}

Results of evaluation of various parameters for validation of HPLC methods for scopoletin and asiatic acid proved that the methods are sufficiently sensitive (LOQ of $0.08 \mathrm{ng} / \mathrm{ml}$ and $7.7 \mu \mathrm{g} / \mathrm{ml}$, respectively), repeatable $(\% \mathrm{RSD}<2)$, reproducible $(\% \mathrm{RSD}<2)$ and accurate (recovery of $98-102 \%$ ) for their reliable quantification (Table 3) in the herbal products containing respective herbs. The method was found to be sufficiently robust as change in Rt $(-0.45$ to +0.80 min for scopoletin and -0.86 to $+0.90 \mathrm{~min}$ for asiatic acid) as well as $\%$ change in content of scopoletin $(-1.41$ to $+1.62 \%)$ and asiatic acid $(-0.81$ to $+2.42 \%)$ was not significant after deliberate changes in chromatographic conditions were made (Supplementary Data). The maximum change in Rt of scopoletin was brought by decrease in flow rate, which is an expected change whereas the maximum change in\% content of scopoletin was brought about by detection at higher $\lambda$ em and $\lambda e x(+1.62 \%)$ as well as by using the buffer having lower $\mathrm{pH}(-1.41 \%$ at $\mathrm{pH} 3.4)$. These results suggested that quantification of scopoletin is insignificantly affected by mild changes in $\mathrm{pH}$ and detection wavelengths. Maximum change in Rt of asiatic acid was caused by change in mobile phase composition ( \pm 0.9 min by $\pm 1 \%$ change in acetonitrile content), and use of INERTSIL column shifted the Rt by $+0.82 \mathrm{~min}$. The $\%$ change in content of asiatic

\begin{tabular}{|c|c|c|c|c|c|c|}
\hline $\begin{array}{l}\text { Validation } \\
\text { Parameter }\end{array}$ & \multicolumn{3}{|c|}{ Scopoletin } & \multicolumn{3}{|c|}{ Asiatic acid } \\
\hline Linearity & \multicolumn{3}{|c|}{$1-500 \mathrm{ng} / \mathrm{ml}$} & \multicolumn{3}{|c|}{$10-1000 \mu \mathrm{g} / \mathrm{ml}$} \\
\hline $\begin{array}{l}\text { Calibration equation } \\
\left(y=m x+c ; r^{2}\right)\end{array}$ & \multicolumn{3}{|c|}{$\begin{array}{c}y=607130.2( \pm 37585.3) x+ \\
1361201.5( \pm 4761.9) ; 0.9991\end{array}$} & \multicolumn{3}{|c|}{$\begin{array}{l}y=4834106( \pm 31397.1) x+ \\
44179.9( \pm 3730.5) ; 0.9980\end{array}$} \\
\hline \multicolumn{7}{|l|}{ LOD } \\
\hline Calculated & \multicolumn{3}{|c|}{$0.026 \mathrm{ng} / \mathrm{ml}$} & \multicolumn{3}{|c|}{$2.7 \mu \mathrm{g} / \mathrm{ml}$} \\
\hline $\begin{array}{l}\text { Tested } \\
\text { (mean; \% RSD) }^{\mathrm{a}}\end{array}$ & \multicolumn{3}{|c|}{$0.030 ; 1.6$} & \multicolumn{3}{|c|}{$3.2 ; 1.56$} \\
\hline \multicolumn{7}{|l|}{ LOQ } \\
\hline Calculated & \multicolumn{3}{|c|}{$0.078 \mathrm{ng} / \mathrm{ml}$} & \multicolumn{3}{|c|}{$7.7 \mu \mathrm{g} / \mathrm{ml}$} \\
\hline $\begin{array}{l}\text { Tested } \\
\text { (mean; \% RSD) }^{\mathrm{a}}\end{array}$ & \multicolumn{3}{|c|}{$0.098 ; 1.02$} & \multicolumn{3}{|c|}{$10.2 ; 1.96$} \\
\hline \multicolumn{7}{|l|}{ Precision studyb } \\
\hline Conc. tested & 1.0 & 50.0 & 500.0 & 10.0 & 100.0 & 1000.0 \\
\hline $\begin{array}{l}\text { Intraday precisiona } \\
\text { (mean; \% RSD) }\end{array}$ & $1.00 ; 1.00$ & $\begin{array}{c}49.12 \\
1.75\end{array}$ & $\begin{array}{c}498.07 \\
0.28\end{array}$ & $9.6 ; 1.04$ & $\begin{array}{c}101.8 \\
1.96\end{array}$ & $\begin{array}{l}984.5 \\
0.26\end{array}$ \\
\hline $\begin{array}{l}\text { Interday precision }^{c} \\
\text { (mean; \% RSD) }\end{array}$ & $0.98 ; 1.02$ & $\begin{array}{c}49.10 \\
1.43\end{array}$ & $\begin{array}{c}498.36 \\
0.05\end{array}$ & $9.6 ; 1.04$ & $\begin{array}{c}104.9 \\
0.86\end{array}$ & $\begin{array}{l}1001.7 \\
1.45\end{array}$ \\
\hline \multicolumn{7}{|l|}{ Recovery studies $^{b}$} \\
\hline Conc. added & 1.0 & 10.0 & 250.0 & 10.0 & 50.0 & 500.0 \\
\hline $\begin{array}{l}\text { Conc. found } \\
\text { (mean; \%RSD)c }\end{array}$ & $1.00 ; 1.00$ & $\begin{array}{c}10.18 \\
0.88\end{array}$ & $\begin{array}{c}248.94 \\
0.37\end{array}$ & $10.2 ; 0.5$ & $49.6 ; 1.6$ & $\begin{array}{l}492.3 \\
1.8\end{array}$ \\
\hline$\%$ Recovery & 100.34 & 101.79 & 99.58 & 101.82 & 99.26 & 98.46 \\
\hline
\end{tabular}

${ }^{\mathrm{a}} \mathrm{n}=6,{ }^{\mathrm{b}}$ all concentration of scopoletin in $\mathrm{ng} / \mathrm{ml}$ and of asiatic acid in $\mu \mathrm{g} / \mathrm{ml},{ }^{\mathrm{c}} \mathrm{n}=3$

Table 3: Validation data of HPLC methods for scopoletin and asiatic acid.

\begin{tabular}{|l|c|c|c|c|c|c|}
\hline \multirow{2}{*}{$\begin{array}{l}\text { Stability } \\
\text { sample }\end{array}$} & Al & All & Alll & BI & BII & B III \\
\hline Control & $185.08 \pm 0.11$ & $165.78 \pm 0.27$ & $206.15 \pm 0.66$ & $6.86 \pm 0.22$ & $2.61 \pm 0.09$ & $28.78 \pm 0.21$ \\
\hline AS 1 & $178.59 \pm 0.19$ & $155.10 \pm 0.16$ & $195.55 \pm 0.52$ & $6.66 \pm 0.06$ & $2.54 \pm 0.08$ & $28.09 \pm 0.11$ \\
\hline AS 3 & $168.33 \pm 0.20$ & $147.31 \pm 0.46$ & $185.41 \pm 0.28$ & $6.40 \pm 0.02$ & $2.45 \pm 0.08$ & $27.02 \pm 0.12$ \\
\hline AS 6 & $159.63 \pm 0.27$ & $138.48 \pm 0.24$ & $175.85 \pm 0.54$ & $6.22 \pm 0.05$ & $2.36 \pm 0.04$ & $26.05 \pm 0.27$ \\
\hline
\end{tabular}

Table 4: Scopoletin content in control and accelerated stability samples of products $A$ and B after 1 month (AS1), 3 months (AS2) and 6 months (AS6).

\begin{tabular}{|l|c|c|c|}
\hline \multirow{2}{*}{ Stability sample } & \multicolumn{3}{|c|}{ Asiatic acid $(\boldsymbol{\mu g} / \mathbf{m l})$} \\
\cline { 2 - 4 } & BI & BII & BIII \\
\hline Control & $30.14 \pm 0.14$ & $32.68 \pm 0.15$ & $44.92 \pm 0.39$ \\
\hline AS1 & $28.89 \pm 0.19$ & $31.12 \pm 0.25$ & $41.93 \pm 0.22$ \\
\hline AS3 & $27.22 \pm 0.18$ & $28.19 \pm 0.24$ & $38.95 \pm 0.13$ \\
\hline AS6 & $24.66 \pm 1.19$ & $26.79 \pm 0.23$ & $35.39 \pm 0.04$ \\
\hline
\end{tabular}

Table 5: Asiatic acid content in control and accelerated stability samples of product B after 1 month (AS1), 3 months (AS2) and 6 months (AS6).

acid was most affected by detection at lower wavelength $(+2.42 \%$ at $204 \mathrm{~nm}$ ). Lower flow rates also affected the\% content of asiatic acid. These results too showed that the method was suitable for accurate determination of asiatic acid in samples. NUCLEODUR column was found to be suitable for analysis of both the markers in comparison to XTERRA and INERTSIL columns. NUCLEODUR column offered a resolution (Rs) greater than 2 of both asiatic acid and scopoletin peaks from the major adjacent peaks whereas the Rs of the same peaks was less than 1.3 on other two columns. These findings of robustness study suggested that the methods were sufficiently resistant to changes in various chromatographic conditions, and hence can be used reproducibly in different laboratories. The method for bacoside A did not need any validation because it was a known method.

\section{Accelerated stability study}

Comparison of LC-UV chromatograms of stability and control samples of each product through overlay revealed that there was no visible change in LC-UV fingerprint of any of the control sample with respect to its respective control sample of each product (Figures 1 and 2). It suggested that the phytochemical composition of the products remained grossly unaltered during accelerated stability testing. Content of scopoletin in control samples of products AI-AIII was found to be $185.08,165.78$ and $206.15 \mathrm{ng} / \mathrm{ml}$ of the product, respectively whereas it was $6.87,2.61$ and $28.78 \mathrm{ng} / \mathrm{ml}$ in products BI-BIII, respectively (Table 4). It revealed that content of scopoletin varied significantly from batch to batch for the same product (165.78-206.15 ng/ml for A, and 2.61$28.78 \mathrm{ng} / \mathrm{ml}$ for B). Further, the variation was found enormous (about 6-60 times) between products by two different manufacturers (product A versus B), which implied that therapeutic efficacy of a product by different manufacturers is most likely to be widely variable. The content of asiatic acid in products BI - BIII was found to be 30.14, 32.68, 44.92 $\mu \mathrm{g} / \mathrm{ml}$ of the product, respectively (Table 5), which also indicated significant batch to batch variation in the product.

Exposure of the products to accelerated stability conditions resulted in decrease in contents of both scopoletin and asiatic acid (Tables 4 and 5). The level of scopoletin decreased with respect to control by $4-6 \%$ in first month, $10-12 \%$ after three months, and by $14-$ $17 \%$ after six months in products AI-AIII. In product B, the decrease with respect to its respective control was $3-4 \%$ during first month, $7-8 \%$ after three months, and $10.5-11.5 \%$ after six months of storage. Almost similar extent of decrease in content of asiatic acid was noted in stability samples of product B i.e., 7-8\% decrease after one month, $10-15 \%$ decrease after three months and $17-22 \%$ after six months in 
comparison to the control. These results suggest that both the products lose active markers significantly over a period of six months under accelerated stability conditions, and hence their therapeutic efficacy is also suspected to decrease.

\section{LC-PDA studies}

Each of the control and stability sample was analyzed on LC-PDA to ascertain the purity of peaks of markers through UV spectra and purity data (in terms of purity angle and purity threshold). UV spectra of peaks corresponding to scopoletin and asiatic acid in all control and stability samples were found similar to, and overlapping with spectra of corresponding standard marker (Figures 3 and 4 for scopoletin and asiatic acid, respectively). Purity threshold of the marker peak in each control and stability sample was higher than its purity angle (Table 6). These data revealed that the marker peaks noted in control and stability samples were pure and no other peak co-eluted with any of the marker tested. It supported that the methods were highly selective for quantitative determination of the markers.

\section{Conclusion}

Accelerated stability study on three batches of two commercial products of shankhpushpi in combination with $B$. monnieri or $C$. asiatica was carried out for a period of six months in accordance with WHO and ICH guidelines. Samples were withdrawn after 1, 3 and 6

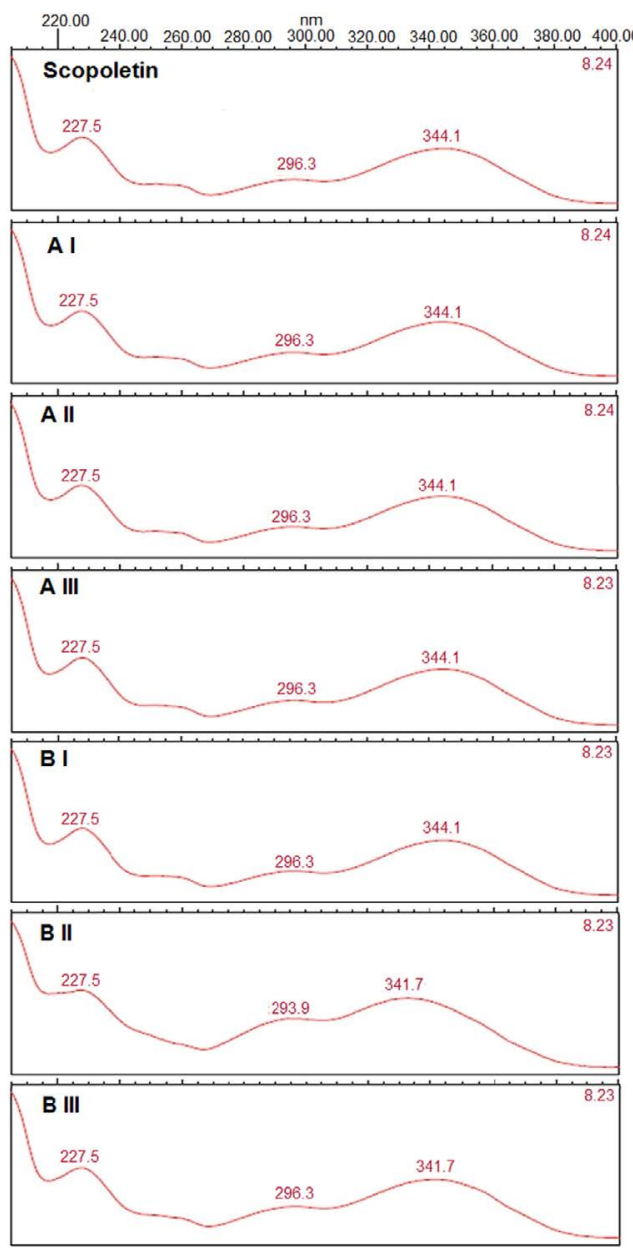

Figure 3: LC-PDA-UV spectra of scopoletin in standard solution and in control samples of products $\mathrm{Al}$ - AIII and $\mathrm{BI}$ - BIII.

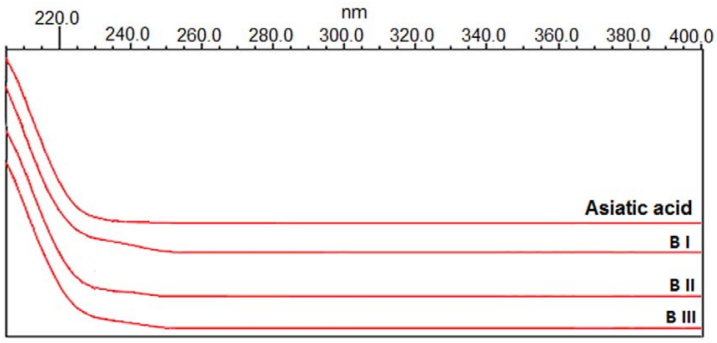

Figure 4: LC-PDA-UV spectra of asiatic acid in standard solution, and in control samples of products $\mathrm{BI}$ - BIII.

\begin{tabular}{|c|c|c|c|c|}
\hline \multirow[t]{2}{*}{ Sample } & \multicolumn{2}{|c|}{ Scopoletin } & \multicolumn{2}{|c|}{ Asiatic acid } \\
\hline & PA & PT & PA & PT \\
\hline Standard & 0.189 & 0.654 & 3.064 & 6.935 \\
\hline $\mathrm{Al}-(\mathrm{C})$ & 0.364 & 0.569 & 3.974 & 5.863 \\
\hline Al-(AS1) & 0.432 & 0.621 & 4.234 & 7.098 \\
\hline Al-(AS3) & 0.231 & 0.734 & 4.983 & 5.607 \\
\hline Al-(AS6) & 0.312 & 0.543 & 3.676 & 5.153 \\
\hline All-(C) & 0.414 & 0.512 & 3.501 & 4.014 \\
\hline All-(AS1) & 0.453 & 0.718 & 5.012 & 5.998 \\
\hline All-(AS3) & 0.522 & 0.648 & 4.821 & 5.362 \\
\hline All-(AS6) & 0.267 & 0.874 & 7.670 & 8.041 \\
\hline Alll-(C) & 0.654 & 0.798 & 4.618 & 4.784 \\
\hline Alll-(AS1) & 0.430 & 0.455 & 5.097 & 5.695 \\
\hline Alll-(AS3) & 0.294 & 0.321 & 6.029 & 7.179 \\
\hline Alll-(AS6) & 0.449 & 0.664 & 7.854 & 8.207 \\
\hline $\mathrm{BI}-(\mathrm{C})$ & 0.533 & 0.610 & 6.942 & 7.112 \\
\hline BI-(AS1) & 0.525 & 0.635 & 3.645 & 4.591 \\
\hline BI-(AS3) & 0.561 & 0.755 & 7.917 & 8.378 \\
\hline BI-(AS6) & 0.219 & 0.302 & 7.143 & 9.452 \\
\hline BII-(C) & 0.568 & 0.590 & 5.613 & 5.998 \\
\hline BII-(AS1) & 0.713 & 0.829 & 7.045 & 7.993 \\
\hline BII-(AS3) & 0.315 & 0.451 & 3.291 & 4.716 \\
\hline BII-(AS6) & 0.309 & 0.565 & 6.116 & 7.221 \\
\hline BIII-(C) & 0.410 & 0.614 & 8.221 & 10.156 \\
\hline BIII-(AS1) & 0.290 & 0.418 & 3.945 & 5.231 \\
\hline BIII-(AS3) & 0.318 & 0.455 & 4.556 & 5.727 \\
\hline BIII-(AS6) & 0.515 & 0.706 & 7.204 & 9.118 \\
\hline
\end{tabular}

Table 6: Purity angle (PA) and purity threshold (PT) of peaks of scopoletin and asiatic acid in standard, control and stability samples.

months, and analysed for content of active markers (scopoletin, asiatic acid and bacoside A) using separate HPLC methods. Scopoletin was determined by HPLC-fluorescent detection method whereas asiatic acid was quantified by HPLC-UV (206 nm) method. Both the methods were found more efficient than the methods known in literature, and were validated in accordance with ICH guidelines Q2 (R1). Bacoside A was not detected in any of the control sample. Content of scopoletin and asiatic acid varied widely among the different batches as well as the two products, which imply a wide therapeutic variability in the products available in the market. The content of markers decreased significantly after 6 months of storage under accelerated conditions, which suggested that therapeutic efficacy of a product decrease substantially with storage. So, there is need to carry out real time studies involving marker's quantification as well as evaluation of therapeutic effects through appropriate in vitro/in vivo methods as per WHO guidelines to establish actual shelf life of the products.

\section{References}

1. Kumari S, Shukla G, Rao AS (2011) The Present Status of Medicinal PlantsAspects and Prospects. Int J Res Pharm Biomed Sci 2: 19-22. 
2. Gohil KJ, Patel JA, Gajiar AK (2010) Pharmacological review on Centella asiatica: a potential herbal cure-all. Indian J Pharm Sci 72: 546-456.

3. Mishra H, Sethiya NK (2010) Review on ethnomedicinal uses and phytopharmacology of memory boosting herb Convolvulus pluricaulis' Choisy. Aust J Med Herb 22: 19.

4. Hornick A, Lieb A, Vo NP, Rollinger J, Stuppner H, et al. (2011) The coumarin scopoletin potentiates acetylcholine release from synaptosomes, amplifies hippocampal long term potentiation and ameliorates anticholinergic- and ageimpaired memory. Neuroscience 197: 280-292

5. Gohil KJ, Patel JA (2010) A Review on Bacopa monniera: Current Research and future prospects. Int J Green Pharm 4: 1-9

6. Drug and Cosmetic (amendment) Rules. 24 Nov, 2005 Rule 161 (B) Ministry of Health and Family Welfare, Department of Ayush, India.

7. Committee for Proprietary Medicinal Products (2003) Stability testing of New Drug Substances and Products. CPMP/ICH/2736/99, European Medicines Agency, London, UK.

8. Committee for Proprietary Medicinal Products (2003) Guideline on stability testing: Stability testing of existing active substances and related finished products. CPMP/QWP/122/02 Rev1 corr, European Medicines Agency, London, UK.

9. Committee on Herbal Medicinal Products (2008) Reflection paper on markers used for Quantitative and Qualitative analysis of Herbal Medicinal Products and Traditional Herbal Medicinal Products. EMEA/HMPC/253629/07, European Medicines Agency, London, UK

10. Committee on Herbal Medicinal Products (2008b) Guideline on Quality of Combination Herbal Medicinal Products/Traditional Herbal Medicinal Products. EMEA/HPMC/CHMP/CVMP/214869, European Medicines Agency, London, UK.

11. Committee on Herbal Medicinal Products (2010) Reflection paper on stability testing of Herbal Medicinal Products and Traditional Herbal Medicinal Products. EMEA/HMPC/3626/09, European Medicines Agency, London, UK.

12. Committee for Medicinal Products for Human use (2011) Quality of Herbal Medicinal Products/ Traditional Herbal Medicinal Products. CPMP/ QWP/2819/00 Rev2, European Medicines Agency, London, UK.

13. Committee for Medicinal Products for Human use (2011b) Test procedures and acceptance criteria for Herbal substances, Herbal preparations and Herbal Medicinal Products/ Traditional Herbal Medicinal Products. CPMP/ QWP/2820/00 Rev2, European Medicines Agency, London, UK

14. World Health Organization (2009) Stability testing of active pharmaceutical ingredients and finished pharmaceutical products. WHO Technical Report Series, No. 953, World Health Organisation, Geneva.

15. United States Food and Drug Administration (2004) Guidance for Industry: Botanical Drug Products. Department of Health and Human Services, Rockville,

16. International Conference on Harmonization (2003) Stability testing of New Drug Substances and Products. ICH Q1A(R2), International Conference on Harmonization, IFPMA, Geneva.

17. Inamdar PK, Yeole RD, Ghogare AB, De Souza NJ (1996). Determination of biologically active constituents in Centella asiatica. J Chromatogr A 742: 127-130.

18. Phrompittayarat W, Wittaya-areekul S, Jetiyanon K, Putalun W, Tanaka H, et al. (2008) Stability studies of saponins in Bacopa monnieri dried ethanolic extract. Planta Med 74: 1756-1763.

19. Srivastava P, Raut HN, Puntambekar HM, Upadhye AS, Desai AC (2010) Stability studies of crude plant material of Bacopa monnieri and its effect on free radical scavenging activity. J Phytol 2: 103-109.

20. Srivastava P, Raut HN, Puntambekar HM, Desai AC (2012) Stability studies of crude plant material of Bacopa monnieri and quantitative determination of Bacopaside I and Bacoside A by HPLC. Phytochem Anal 23: 502-507.

21. Schaneberg BT, Mikell JR, Bedir E, Khan IA, Nachname V (2003) An improved HPLC method for quantitative determination of six triterpenes in Centella asiatica extracts and commercial products. Die Pharmazie-An International Journal of Pharmaceutical Sciences 58: 381-384.

22. Günther B, Wagner H (1996) Quantitative determination of triterpenes in extracts and phytopreparations of Centella asiatica (L.) Urban. Phytomedicine 3: $59-65$
23. Hashim P, Sidek $\mathrm{H}$, Helan MHM, Sabery A, Palanisamy UD, et al. (2011) Triterpene composition and bioactivities of Centella asiatica. Molecules 16 1310-1322.

24. Thongnopnua $P(2008)$ High-performance liquid chromatographic determination of asiatic acid in human plasma. Thai J Pharm Sci 32: 10-16.

25. Rafamantanana MH, Rozet E, Raoelison GE, Cheuk K, Ratsimamanga SU, et al. (2009) An improved HPLC-UV method for the simultaneous quantification of triterpenic glycosides and aglycones in leaves of Centella asiatica (L.) Urb (Apiaceae). J Chromatogr B 877: 2396-2402.

26. Hong SS, Kim JH, Li H, Shim CK (2005) Advanced formulation and pharmacological activity of hydrogel of the titrated extract of Centella asiatica. Archives of pharmacal research 28: 502-508.

27. Tiwari RK, Chanda S, Deepak M, Murli B, Agarwal A (2010) HPLC method validation for simultaneous estimation of madecassoside, asiaticoside and asiatic acid in Centella asiatica. J Chem Pharm Res 2: 223-229.

28. James JT, Meyer R, Dubery IA (2008) Characterisation of two phenotypes of Centella asiatica in Southern Africa through the composition of four triterpenoids in callus, cell suspensions and leaves. Plant Cell, Tissue and Organ Culture 94: 91-99.

29. Randriamampionona D, Diallo B, Rakotoniriana F, Rabemanantsoa C, Cheuk $\mathrm{K}$, et al. (2007) Comparative analysis of active constituents in Centella asiatica samples from Madagascar: application for ex situ conservation and clonal propagation. Fitoterapia 78: 482-489.

30. Grimaldi R, De Ponti F, D'Angelo L, Caravaggi M, Guidi G, et al. (1990) Pharmacokinetics of the total triterpenic fraction of Centella asiatica after single and multiple administrations to healthy volunteers. A new assay for asiatic acid. J Ethnopharmacol 28: 235-241.

31. Li Z, Wang L, Yang G, Shi H, Jiang C, et al. (2003) Study on the determination of polyphenols in tobacco by HPLC coupled with ESI-MS after solid-phase extraction. J Chromatogr Sci 41: 36-40.

32. Xia Y, Dai $Y$, Wang Q, Liang $\mathrm{H}$ (2007) Determination of scopoletin in rat plasma by high performance liquid chromatographic method with UV detection and its application to a pharmacokinetic study. J Chromatogr B 857: 332-336.

33. Müller-Enoch D, Greischel A (1988) A direct HPLC-method for measuring cytochrome P-450 activities with scoparone as substrate. Cellules Hépatiques Et Médicaments 164: 86

34. Upadhyay V, Sharma N, Tiwari AK, Joshi HM, Malik A, et al. (2013) Standardization of HPLC method of Scopoletin in different extracts of Convolvulus pluricaulis. Int J Pharm Sci Drug Res. 5: 28-31.

35. Shinde PB, Katekhaye SD, Mulik MB, Laddha KS (2014) Rapid simultaneous determination of marmelosin, umbelliferone and scopoletin from Aegle marmelos fruit by RP-HPLC. J Food Sci Technol 51: 2251-2255.

36. Arunachalam KD, Kuruva JK, Hari S, Annamalai SK, Bharkaran KV (2015) HPTLC fingerprint analysis and phytochemical investigation of Morinda tinctoria Roxb leaf extracts by HPLC and GC MS. Int J Pharm Pharm Sci 7: 360-366.

37. Pachauri SD, Khandelwal K, Bhaisora M, Pandey RR, Srivastava A, et al (2014) The preparation of Morinda citrifolia (Noni)-phospholipid complex and its pharmacokinetics study in rats. J Biomater Tissue Eng 4: 221-226.

38. Lin, Chian-Yei, Horng-Liang Lay (2013) Characteristics of fruit growth, component analysis and antioxidant activity of mulberry (Morus spp.). Sc Horticult 162: 285-292.

39. JunJun A, AiJing L, XiaoMei G, WenJie Z, Di L, et al. (2015) HPLC determination of the eight constitutes in Portulaca oleracea $\mathrm{L}$. from different locations. Eur $\mathrm{J}$ Med Plants 5: 156-164

40. Yang ZN, Sun YM, Luo SQ, Chen JW, Yu ZW, et al. (2014) Quality evaluation of Houttuynia cordata Thunb. by high performance liquid chromatography with photodiode-array detection (HPLC-DAD). Pak J Pharm Sci 27: 223-231.

41. Luján L, María L, Assanga I, Bernard S, Rivera-Castañeda EG, et al. (2014) Nutritional and phenolic composition of Morinda citrifolia (noni) fruit at different ripeness stages and seasonal patterns harvested in Nayarit, Mexico. Int J Nutr Food Sci 3: 421

42. Risner $\mathrm{CH}$ (1994) The determination of scopoletin in environmental tobacco smoke by high-performance liquid chromatography. J Liq Chromatogr Re Technol 17: 2723-2736.

43. Izquierdo MF, Granados JQ, Mir MV, Martinez ML (2000) Comparison of methods for determining coumarins in distilled beverages. Food Chem 70: 251-258. 
Citation: Bansal NY, Bansal G (2015) HPLC-UV/FD Methods for Scopoletin and Asiatic acid: Development, Validation and Application in WHO Recommended Stability Testing of Herbal Drug Products. Biochem Anal Biochem 4: 207. doi:10.4172/2161-1009.1000207

Page 8 of 8

44. Joanna S, Kadzinski L, Banasiuk R, Gwizdek-Wisniewska A, Olry A, et al. (2014) Identification of QTL affecting scopolin and scopoletin biosynthesis in Arabidopsis thaliana. BMC Plant Biol 14: 280.

45. Fallon A, Booth RFG, Bell LD (1987) Applications of HPLC in Biochemstry. In Laboratory Techniques in Biochemistry and Molecular Biology, Budon $\mathrm{RH}$, van Knippenberg PH (Eds), Elsevier Science Publishers B.V. (Biomedical Division), Amsterdam.

46. Guilbault GG (1990) Practical Fluorescence Modern Monographs in Analytical Chemistry. 3 (2nd edn) Marcel Dekker Inc, New York.

47. International Conference on Harmonization (2005) Validation of Analytical Procedures: Methodology. Q2B (CPMP//CH/281/95), International Conference on Harmonization, IFPMA

48. Baidyanath (2011) Ayurveda - Sar Sangrah, Shri Baidyanath Ayurveda Bhawan Ltd, Allahabad, India.
49. Khare CP (2003) Indian Herbal Remedies: Rational Western Therapy and Other Traditional Usage, Botany. Springer verlag berlin Heidelberg New York.

50. Joanna S, Kadzinski L, Banasiuk R, Gwizdek-Wisniewska A, Olry A, et al. (2014) Identification of QTL affecting scopolin and scopoletin biosynthesis in Arabidopsis thaliana. BMC Plant Biol 14: 280.

51. Izquierdo MF, Granados JQ, Mir MV, Martinez ML (2000) Comparison of methods for determining coumarins in distilled beverages. Food Chem 70: 251 258.

52. Risner $\mathrm{CH}$ (1994) The determination of scopoletin in environmental tobacco smoke by high-performance liquid chromatography. J Liq Chromatogr Relat Technol 17: 2723-2736

53. Müller-Enoch D, Greischel A (1988) A direct HPLC-method for measuring cytochrome P-450 activities with scoparone as substrate. Cellules Hépatiques Et Médicaments 164: 86 